\title{
Respiratory disorders in endurance athletes - how much do they really have to endure?
}

This article was published in the following Dove Press journal:

Open Access Journal of Sports Medicine

2 April 2014

Number of times this article has been viewed

\section{Maurizio Bussotti \\ Silvia Di Marco \\ Giovanni Marchese \\ Cardiac Rehabilitation Unit, Fondazione Salvatore Maugeri, Milan, Italy}

Correspondence: Maurizio Bussotti Fondazione Salvatore Maugeri, Unità di Cardiologia Riabilitativa, Via Camaldoli 64, 20138 Milan, Italy

Tel +39250725 I 4 I

Fax +39250725290

Email maurizio.bussotti@fsm.it

\begin{abstract}
Respiratory disorders are often a cause of morbidity in top level endurance athletes, more often compromising their performance and rarely being a cause of death. Pathophysiological events occurring during exercise, such as bronchospasm, are sometimes followed by clear pathological symptoms represented by asthma related to physical exertion or rarely by pulmonary edema induced by a strenuous effort. Both bronchospasm and the onset of interstitial edema induced by exercise cannot be considered pathological per se, but are more likely findings that occur in several healthy subjects once physical exhaustion during exertion has been reached. Consequently, we get a vision of the respiratory system perfectly tailored to meet the body's metabolic demands under normal conditions but which is limited when challenged by strenuous exercise, in particular when it happens in an unfavorable environment. As extreme physical effort may elicit a pathological response in healthy subjects, due to the exceeding demand in a perfectly functional system, an overview of the main tools both enabling the diagnosis of respiratory impairment in endurance athletes in a clinical and preclinical phase has also been described.
\end{abstract}

Keywords: exercise, athlete, ventilation, bronchoconstriction

\section{Introduction}

In the early decades of the last century, literature reported anecdotal reports of isolated cases of athletes with respiratory disorders arising during exercise. Studies published in the 1980s described these specific pathological manifestations in athletes of endurance disciplines. In 1981, Mahler et al recorded forced expiratory flow volume loops (FVL) in 15 runners before and after an ultramarathon ( 80.6 to $100 \mathrm{~km})$ to evaluate the results of hard exercise on lung function. ${ }^{1}$ They observed a significant decrease postrace in forced vital capacity (FVC), in forced expiratory volume in 1 second $\left(\mathrm{FEV}_{1}\right)$, in peak expiratory flow, and in flow at $50 \%$ of FVC that improved by 2.5 hours after the race. The authors inferred that the reduction in flow rates after ultramarathon running could be explained by a temporary airway obstruction and the restoration of the initial lung function and gradual improvement of the decrease of FVC with rest and nourishment by the development of respiratory muscle fatigue. Just a few years later, in 1984, Dempsey focused his attention on exercise-induced arterial hypoxemia (EIAH) in healthy subjects, describing endurance-trained runners experiencing significant desaturation. ${ }^{2}$

In the last 30 years from this initial description, an interesting debate has been developing about the limitations of the respiratory system in absolutely healthy subjects. These studies implied a limited capacity by the respiratory system to adapt to chronic physical training, as is already stated in chronic hypoxia ${ }^{3}$ or lung resection ${ }^{4}$ 
and demonstrated in the peripheral muscles and the cardiovascular system.

Actually, exercise training involves every component of the $\mathrm{O}_{2}$ transport and metabolic system, except the lungs. Only hypoxia in early life and extensive lung resection have been proven to stimulate growth in normal lungs across species. $^{5}$

Many causes can limit pulmonary performance. First, flow limitation may occur in intrathoracic airways during exercise because of bronchoconstriction phenomena or due to an excessive ventilatory demand superimposed on a normal maximum flow-volume envelope. ${ }^{6-8}$ Narrowing of the extrathoracic upper airways also occurs in some athletes at very high flow rates during heavy exercise..$^{9,10}$ Second, EIAH occurs when alveolar-arterial $\mathrm{O}_{2}$ pressure difference excessively widens, ${ }^{2}$ attributable both to the opening of small intracardiac or intrapulmonary shunts ${ }^{11,12}$ during exercise and to the interstitial edema formation. ${ }^{13,14}$ Finally, fatigue of the respiratory muscles, particularly of the diaphragm, can have a vasoconstrictor effect on limb muscle vasculature compromising $\mathrm{O}_{2}$ transport and the overall performance. ${ }^{15}$

From all of the above, we can draw the paradoxical idea that the fitter someone is, the more likely he will experience respiratory limitations. This is different from the favorable remodeling effect determined by physical training on the lungs in chronic respiratory diseases. ${ }^{16}$ This implies that chronic physical training per se might arouse a faulty adaptation of the main lung components, at the alveolar-capillary interface or at the airway level, particularly when exertion is carried on in particular environmental locations, as in cold ${ }^{17}$ or in hypoxic conditions at even moderately high altitude. The result is that the negative influences of these respiratory system limitations will be greatly intensified during exercise performance, especially in highly fit individuals.

Consequently, the debate if the lung can be defined "overbuilt" or "underbuilt" for facing strenuous exercise has been recognized as intriguing by the scientific community. ${ }^{18}$ The latest scientific reports support the hypothesis of a fully attained function of the lung to satisfy the metabolic demands in normal conditions (ie, levels of physical activity at sea level), but severely impaired during high level exercise or in extreme environmental conditions. The aim of this review is to outline the most frequently described respiratory disorders challenging the endurance athletes: the dramatic side effects, such as the sudden death; the prevalence and incidence of exercise-induced respiratory disorders in the athletes; miscellaneous of clinical respiratory findings due to exertion performed in extreme conditions; diagnosis, preclinical screening methods, and therapy.

\section{Introduction to risk factors for unexplained death in athletes}

When talking about respiratory disorders we think of the pathophysiological changes induced by intense exercise that can be a cause of morbidity or limitation on athletic performance by itself. In fact, we almost always forget to think of respiratory disorders as a possible cause of sudden death. Actually, it is noteworthy that doing a PubMed search on the topic of sudden death, only few studies among so many pay attention to respiratory causes. Most continue to list a long series of cardiovascular abnormalities reliably or surely related to sudden death. Consequently, we could derive the illusory belief that competitive athletes suffering from asthma are not at risk for sudden death during sports.

Actually, in each one of the examined case series of sudden death, undetermined or noncardiac causes, as the respiratory ones, have been more frequently recorded in the younger groups ( $<30$ years) which include most of the professional athletes, while in the groups aged more than 30 years, cardiac causes are prevalent. ${ }^{19}$ Over a 27-year period, from 1980 to 2006, data on 1,866 fatal events (including survivors of cardiac arrest) in young athletes participating in organized competitive sports were both prospectively and retrospectively collected and included in a wide registry, the US National Registry of Sudden Death in Athletes instituted at the Minneapolis Heart Institute Foundation. ${ }^{20}$ Of these, 1,049 deaths $(56 \%)$ were probably or definitely attributed to cardiovascular causes; among these hypertrophic cardiomyopathy was the most common, occurring in 251 cases (36\%). Among nontraumatic causes of death $(n=182 ; 10 \%)$, heat stroke, illicit drug use, and pulmonary diseases (asthma with status asthmaticus $[\mathrm{n}=15]$ or pulmonary embolism $[\mathrm{n}=13]$ ) were the most common.

The danger of a severe bronchoconstriction elicited by exercise was highlighted by a population based study on young adults in which 61 of 263 sports related fatalities were related to asthma exacerbation. ${ }^{21}$ Among those occurring in competitive athletes, $51 \%$ occurred while participating in organized sports. Only one of the 61 athletes used inhaled steroids. In this study by Becker et al, even racial and sex distribution were considered; athletes with a history of asthma who died during sporting activities were largely white, at a nearly $2: 1$ ratio to blacks; and male versus female subjects, at a 2:1 ratio, in comparison with a commonly reported ratio of $1.5: 1 .^{21}$ 
Severity of disease is also important. Even though severe pathological conditions are rare among athletes and a subject with history of mild asthma may unexpectedly die, usually death for sudden symptomatic asthma occurs in the severely afflicted population or in those individuals who are poorly compliant to therapy or recently hospitalized for exacerbation. ${ }^{21}$ The greater attention paid recently to asthma in the sport population has led not only sports doctors, but even coaches, to put in place more accurate preventive measures to diagnose and treat patients with this disease. ${ }^{22}$

But there is not only asthma. We must take into account cases of pulmonary edema (PE). These may be quite rare after a strong effort ${ }^{23-25}$ but are more frequent and severe at high altitude. High altitude pulmonary edema (HAPE) can have mortality rates up to $40 \%$ where there is limited medical care, ${ }^{26}$ but fortunately, this problem is of little regard to endurance athletes because altitudes at which they train are normally below $2,000-2,500 \mathrm{~m} \cdot{ }^{27}$

\section{The prevalence and incidence of exercise-induced respiratory disorders in athletes}

The most frequent respiratory ailments of athletes are related to a mismatch between airway caliber and increased ventilation caused by exercise. We can group them into three classes: 1) disorders related to alterations of the bronchial tone; 2) expiratory flow limitation (EFL) in nonasthmatic subjects; and 3 ) disorders of the extrathoracic upper airway.

In actively competing athletes, particularly in the elite endurance athletes, an increasing prevalence of exerciseinduced asthma (EIA) or exercise-induced bronchoconstriction (EIB) has been widely recorded. EIA and EIB are terms used to describe the clinical phenomena related to transient narrowing of the airways that follows vigorous exercise. Specifically, the term EIA is more appropriately used to describe symptoms and signs of asthma (bronchoconstriction and symptoms of dyspnea, cough, or wheezing) provoked by exercise, while the same clinical presentation in subjects without asthma is defined as EIB. ${ }^{28-31}$ Conversely, bronchial hyperresponsiveness (BHR) identifies a positive bronchial provocation test to a physical stimulus like exercise, dry air hyperpnea or hyperosmolar aerosols, or to a pharmacological stimulus such as inhaled methacholine or histamine. ${ }^{28}$

Despite large variations in prevalence between sports and reports, EIA, EIB, and/or BHR are some of the most common chronic medical findings in Olympic athletes. ${ }^{32,33}$ Although EIA and EIB can impair athletic performance, many athletes with these disorders were able to achieve important goals. Amy Van Dyken, for example, an athlete who suffered from relatively severe asthma, won four gold medals in swimming in the 1996 Olympic Games. Since the 1980s, surveys have reported high prevalence of asthmatic disorders among athletes, but all these papers were questionnaire-based without any objective demonstration of EIB. ${ }^{28}$ Data collected over the three summer Olympic Games (Atlanta in 1996, Sydney in 2000, and Athens in 2004) confirmed that endurance athletes were the largest users of inhaled $\beta_{2}$-agonists, with bikers on top ( $15.3 \%$ of all competitors), followed by swimmers $(11.3 \%)$, and pentathletes $(10.1 \%){ }^{28}$

In Sydney in 2000 and in Athens in 2004, the International Olympic Committee - Medical Commission (IOC$\mathrm{MC}$ ) criteria for diagnosing EIA/EIB and/or BHR were introduced and this found a prevalence of $21.2 \%$ of overall athletes with a positive bronchoprovocation test and $20.7 \%$ with a positive bronchodilator test. ${ }^{34}$ High prevalence of BHR $(48 \%)$ to histamine was also found among swimmers. ${ }^{35}$ The Global Allergy and Asthma European Network (GA2LEN) Olympic study reported prevalence of $25 \%$ of asthma symptoms among European athletes participating in the Beijing Olympic Games. ${ }^{32}$

In sports requiring strenuous endurance training, athletes are obliged to inspire large volumes of air, and for this reason an increased risk of developing EIA/EIB may be expected. This risk is further increased if athletes are exposed to cold air. For instance, in Olympic Nordic combined and cross-country, skiers withstand prolonged high levels of ventilation (as much as $200 \mathrm{~L} / \mathrm{min}$ ), often in very low ambient temperatures. ${ }^{36}$ In 1998, EIB was found after a field exercise test in $23 \%$ of all athletes of the American winter Olympic team, with a prevalence of 50\% just among the cross-country skiers. ${ }^{17}$ Another report by Fitch found that endurance winter athletes and especially cross-country skiers (17.2\%) represented the group with the highest number of approved indications for asthma drugs in the 2002, 2006, and 2010 winter Olympic games. ${ }^{33}$ Also for winter sports other than cross-country skiing, reports on increased prevalence of asthma and BHR have been made, including biathlon and Nordic combined, ${ }^{17}$ figure skaters, ${ }^{37}$ ice hockey players, ${ }^{38}$ and speed skaters. ${ }^{17}$ The importance of hyperventilation is demonstrated by another report that documented a prevalence of EIA/EIB of approximately $15 \%$ in cross-country skiers in comparison with a lower one, less than $4 \%$, in their counterparts represented by alpine ski and ski jump who train in similar weather conditions without inhaling huge quantities of cold dry air. ${ }^{36}$ 
From disorders related to alteration of bronchial tone, we must distinguish EFL related to an excessive increase of ventilation and flow rates in subjects with nonasthmatic with normal airways. EFL is supposed to be very frequent in elite endurance athletes, with a prevalence of up to $40 \%$ in men and up to $90 \%$ in women. ${ }^{6-8}$ Sometimes, flow limitation concerns the extrathoracic upper airway. Exercise-induced laryngeal obstruction includes exercise-induced paradoxical arytenoid motion, exercise-induced laryngomalacia, and vocal cord dysfunction (VCD). In elite athletes, the main cause for laryngeal obstruction during exercise appears to be VCD, with a recorded prevalence of approximately $5 \%$ : most of the cases of VCD $(>80 \%)$ are described in female athletes and are often misdiagnosed as asthma. ${ }^{39}$

Other frequent respiratory disorders in athletes are those related to an inefficient alveolar-to-arterial $\mathrm{O}_{2}$ exchange. ${ }^{40}$ Regardless of its numerous causes, this disorder is clinically featured by arterial desaturation, known as EIAH that is commonly manifested by highly trained endurance athletes, with a prevalence of about half the young male and an even larger number of young female athletes developing different degrees of gas exchange impairment during high level exercise. ${ }^{41}$

The literature also describes anecdotal cases of PE that is very rare among athletes. ${ }^{23-25}$ Quite different could be the situation for HAPE, where prevalence in healthy individuals can vary from $0.2 \%$ to $15 \% .{ }^{26}$ Actually, this problem little affects endurance athletes who usually compete at or train at altitudes not exceeding 2,000-2,500 m. At these altitudes, $25 \%$ of athletes can be affected only by a mild and transient form of acute mountain sickness (AMS), consisting of headache, loss of appetite or nausea, insomnia, dizziness, and peripheral edema. ${ }^{27}$ Only sporadically, endurance athletes can be exposed to a more extreme hypoxia (both in normo- and hypobaric conditions) for a short time. This is the case in exposure to altitudes up to 5,000 $\mathrm{m}$ with the intention to increase the endogenous erythropoietin production. Furthermore, to stimulate endurance capacities, athletes can undergo training sessions in normobaric hypoxic conditions equivalent to altitudes of 4,000-5,000 m (intermittent hypoxic training), or to repeated intermittent brief exposures after a few minutes at rest with severe normobaric hypoxia equivalent to altitudes of up to $6,000 \mathrm{~m}$ (intermittent hypoxic exposure). ${ }^{27}$ Despite the severe level of hypoxia, there is no risk of developing AMS, high altitude cerebral edema (HACE), and HAPE because AMS needs about 6-8 hours to develop, and HACE or HAPE occur only after continuous exposures of at least 2 days above threshold altitudes of 4,000 $\mathrm{m}$ and 3,000-3,500 $\mathrm{m}$, respectively.
Swimming-induced PE is another rare type of PE, typical of well-trained swimmers after a heavy swimming session, characterized by typical symptoms of PE and a pulmonary restrictive pattern which tends to regress over a week. ${ }^{42}$

Finally, we must remember infective diseases. Symptoms indicative of upper respiratory tract infections account for $30 \%$ to $40 \%$ of examinations in sports medicine clinics by elite athletes. Rhinitis is a common finding in athletes with a prevalence $>30 \%$, and particularly in swimmers where it is as high as $74 \%{ }^{43}$

\section{Outline of the athletic population most at risk}

The previous definitions of EIA, EIB, and BHR allows the distinction of a nearly physiological response from a pathological condition, with a pathogenesis of bronchoconstriction supposed to be different in those with pre-existent asthma compared to those with only exercise-induced symptoms. ${ }^{32}$ Indeed, bronchoconstriction phenomena appear to be quite heterogeneous. Recently, Haahtela et al proposed to differentiate two different clinical phenotypes of asthma in athletes. ${ }^{44}$ The first phenotype is the classical pattern of asthma, characterized by early onset in childhood, responsive to methacholine, atopy and signs of eosinophilic airway inflammation, and increased $\mathrm{F}_{\mathrm{E}} \mathrm{NO}$ (expiratory fraction of nitric oxide) levels. The second one should be characterized by a late onset of symptoms during sporting activity, bronchial responsiveness to eucapnic voluntary hyperventilation (EVH) but not necessarily to methacholine, with a variable response of atopic markers and $\mathrm{F}_{\mathrm{E}} \mathrm{NO}$. For some of the athletes of this second group, in which respiratory distress is caused only by extreme exercise and severe airway cooling/drying, EIB may really be considered a physiological phenomenon. ${ }^{32}$ Furthermore, for subjects of the first phenotype, the natural history of EIA is unclear and supposed to be different for elite athletes.

Several risk factors for EIA/EIB have been reviewed: family history of atopy, positive skin prick testing, allergic rhinitis, and eczema. Atopy is a major risk factor together with the type of training. ${ }^{45}$ The risk of asthma increases 25-fold in anaerobic atopic athletes and even 75-fold in aerobic atopic athletes, compared to nonatopic athletes. ${ }^{46}$

Specific sport environments markedly increase the likelihood of EIA/EIB. In fact, elite swimmers or runners, especially those who take part in endurance sports and winter sports athletes, are more exposed to allergens. ${ }^{46}$ Symptoms of EIB are ultimately triggered by chemicals, insecticides, pesticides, and fertilizers. ${ }^{31,46}$ It is noteworthy to underline that athletes are particularly liable to injuries to the airway epithelium when they 
are requested to sustain high level exercise, with consequent high ventilation demand, especially when additionally exposed to environmental unfavorable conditions (ie, polluted air, cold dry air, or chlorinated indoor pools). ${ }^{28,30-33}$ The prevalence of exercise-induced respiratory disorders in elite athletes just mentioned in the previous paragraph ${ }^{17,28,32-36}$ is congruent with the assumption that the ventilatory demands combined with the training environment are determining factors in the development of EIB, EIA, and/or BHR. Moreover, this explains the large variations in prevalence of respiratory disorders existing between sports that are apparently equivalent, eg, the difference between athletes competing in similar weather conditions (very low ambient temperatures) such as cross-country skiers (prolonged high levels of ventilation) and alpine skiers (not inhaling large quantities of cold dry air). ${ }^{36}$ Further proof of the role played by the environment in the increased risk for developing EIB or EIA has been suggested in athletes exposed to allergens, pollutants, or airborne irritants. ${ }^{45,46}$

Most of the clinical data have an explanation in the pathogenetic cascade induced by the severe hyperpnoea achieved during high level exercise. It would be responsible not only for the exposition of the airway epithelium, but also for the increased shear stress and transmural pressure gradients, so that all together, the last ones would have, as a result, the sloughing or even a complete detachment of dehydrated epithelial cells. $^{47}$

Finally, the repeated sequence of stretching and compressing of airway epithelial cells performed at high flow rates may determine a negative effect on the functioning of the epithelial cells. Notwithstanding the airway epithelium's intrinsic capability to repair itself rapidly, the reiterated injury-repair process would be the cause of structural and functional changes, ${ }^{47}$ named "airway remodeling", often highlighted by bronchoscopy of elite swimmers ${ }^{48}$ and crosscountry skiers. ${ }^{36}$

On the other hand, the late development of BHR after many years of training, often verified in elite athletes, is consistent with a slow and progressive process whereby over time the contractile properties of the bronchial smooth muscle are modified by the injury-induced plasma exudation, ${ }^{47}$ as well as to a greater extent biased by the inhalation of cold dry air or of noxious agents, such as byproducts of chlorination and airborne pollutants. ${ }^{49}$ The same hyperpnoea and maybe the low air humidity lead to a rapid evaporation of water from the airway surface liquid. This becomes hyperosmolar and draws water from any cell nearby, causing cells to dry up and consequently release inflammatory mediators that can promote bronchoconstriction. ${ }^{32}$
Furthermore, the inhalation of cold dry air and subsequent dehydration act as an additional stress, the "thermal stress", by which the airway's cooling during exercise is followed by fast rewarming once at rest. ${ }^{50}$ The cooling of airways causes a parasympathetic-mediated bronchoconstriction, with, at first, a vasoconstriction of bronchial venules. The rewarming at the end of exercise causes a vasodilation with mucosal edema. All these mechanisms reduce the size of the bronchial lumen. ${ }^{17}$

Sometimes, cross-country skiers have BHR only when bronchial challenge with methacholine is administered, due to both the enhanced access to the $\mathrm{M}_{3}$ muscarinic receptors on bronchial smooth muscle and the abovementioned process of change in contractility following injury and repair of the epithelial barrier. ${ }^{51}$ Images of the airways, obtained by magnetic resonance (MR) with hyperpolarized helium, confirm the presence, during exercise-induced bronchoconstriction phenomena, of areas of closure or near closure of segmental airways in the lungs during EIB. ${ }^{52}$

\section{Clinical presentation and diagnosis EIA, EIB, and BHR}

Diagnosis of asthma is typically clinical and based on the history of recurring episodes of bronchial obstruction, physical examination, and signs indicating the presence of bronchial obstruction..$^{53}$ The competing athlete frequently reports the presence of respiratory symptoms in relationship to exercise, but the diagnosis of EIA or EIB may be difficult because of the variability and nonspecificity of symptoms.

Criteria for the diagnosis of EIA, EIB, and/or BHR in athletes are documented. ${ }^{28}$ Actually, since 2002, the IOC$\mathrm{MC}$ required a combination of symptoms and objective criteria such as positive exercise test, positive bronchodilator test, or the presence of BHR to direct (eg, methacholine or histamine) or indirect (eg, EVH, inhalation of cold dry air, dry air, hyperosmolar aerosols like hypertonic saline, and inhalation of mannitol and adenosine monophosphate). ${ }^{54,55}$ Generally, it might be stated that indirect tests are more specific for asthma, whereas the direct tests are more sensitive.

In the $1980 \mathrm{~s}, \mathrm{EIB}$ was reported in $70 \%-80 \%$ of the asthmatic patients. ${ }^{56}$ However, presently this has changed dramatically with the widespread use of anti-inflammatory treatment of asthma with inhaled corticosteroids.

EIB is established by a decline in the $\mathrm{FEV}_{1}$ which confirms airway obstruction (Figure 1). ${ }^{57}$ The intensity of the bronchoconstriction typically reaches its peak at 5 to 10 minutes after an exhaustive exercise and usually 


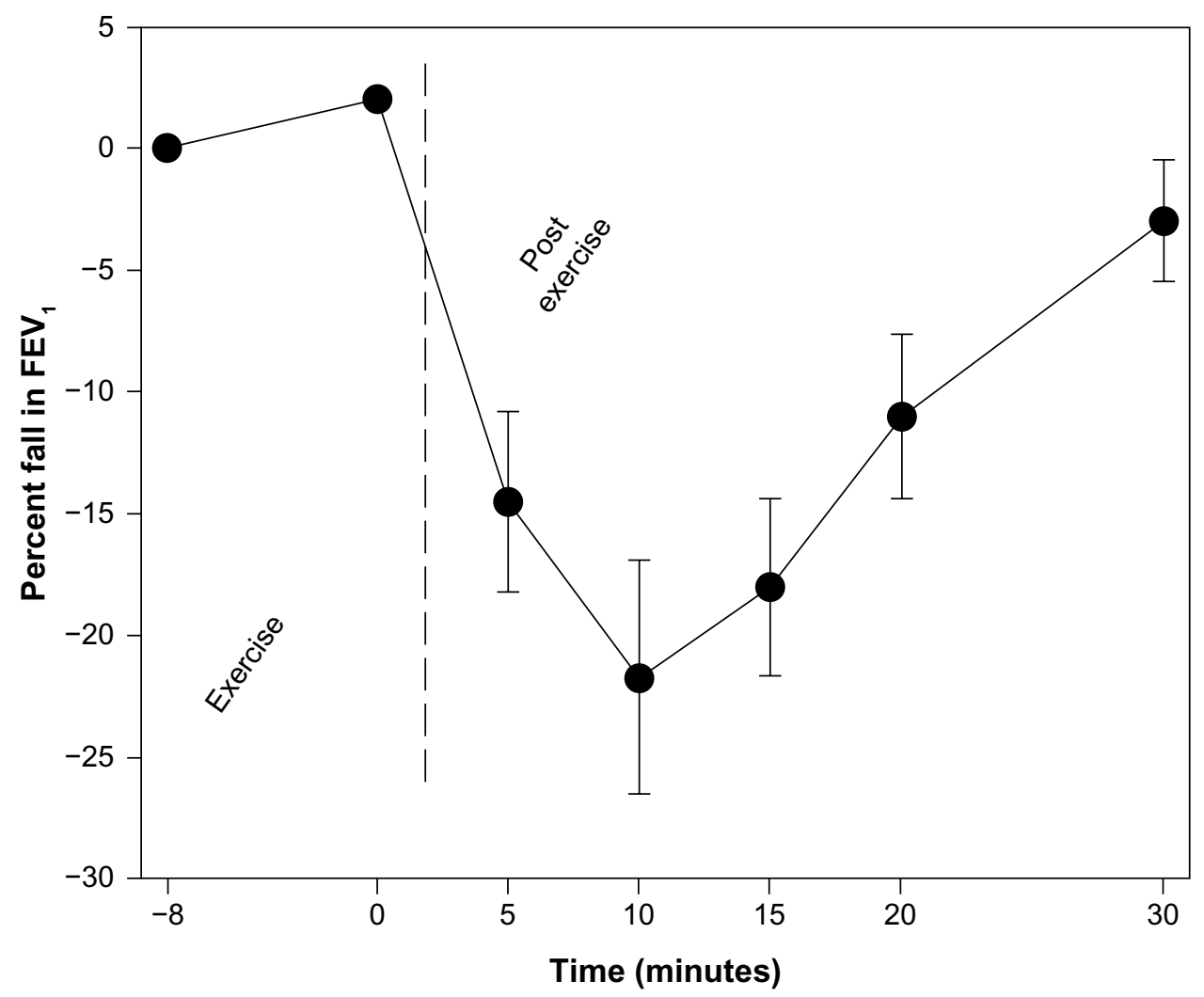

Figure I Typical change in forced expiratory volume in I second in response to an 8 minute exercise challenge in exercise-induced bronchoconstriction (EIB)-positive individuals.

Notes: Note the small improvement in forced expiratory volume in I second (FEV) immediately after exercise followed by significant falls in FEV at 5 minutes after the cessation of exercise. Spontaneous recovery is most often nearly complete by 30 minutes postchallenge. Recovery can be accelerated by administration of an inhaled $\beta_{2}$-agonist. Reprinted from J Allergy Clin Immunol, 122, Rundell K, Slee J, Exercise and other indirect challenges to demonstrate asthma or exercise-induced bronchoconstriction in athletes, 238-246, copyright (2008), with permission from Elsevier. ${ }^{53}$

ceases about 60 minutes thereafter. ${ }^{57} \mathrm{~A}$ distinctive clinical element of EIB is the so-called refractory period, visible when exercise is repeated within 1 to 3 hours with less of an EIB response. ${ }^{29}$

Similar to typical asthma symptoms, patients with EIB will describe cough, chest tightness, wheezing, and shortness of breath.

Differential diagnosis of EIB should embrace deconditioning, obesity, upper airway obstruction such as VCD or laryngomalacia, anxiety-related hyperventilation, as well as other cardiac and pulmonary abnormalities. ${ }^{39,49}$

The latest American Thoracic Society guidelines recommend that the exercise should be exhaustive, conducted for a minimum of 8 minutes without warming up and designed to be as sport specific as possible, with a workload corresponding to $95 \%$ of maximum heart rate during the last 4 minutes, with inhalation of air with a relative humidity below $50 \%$ and an ambient temperature of $20^{\circ} \mathrm{C}-25^{\circ} \mathrm{C} .{ }^{58}$ An exercise challenge involves measuring $\mathrm{FEV}_{1}$ before exercise and at 3, 5, 10, and 15 minutes after stopping exercise. It was demonstrated that EIB is heavily influenced by the humidity and temperature of the inhaled air, and that the use of inhaled cold air $\left(-20^{\circ} \mathrm{C}\right)$ during exercise testing markedly increased the sensitivity in diagnosing EIB without decreasing specificity. ${ }^{58}$

For exercise tests (in laboratory or in field), both the European Respiratory Society (ERS) and the American Thoracic Society recommend observing a fall in $\mathrm{FEV}_{1}$ of $10 \%$ from baseline for the test to be considered positive. ${ }^{58,59}$ Exercise challenge tests performed both in the laboratory and in the field have been proven to have a high specificity for EIB. However, laboratory exercise tests have only a moderate sensitivity for EIB in elite athletes, while those performed in the field lack standardization. ${ }^{60}$ The laboratory test may be the demonstration of reversibility to an inhaled bronchodilator. This is of value to detect airway obstruction, but has limited value as a basis for diagnosis of asthma. The bronchodilator response is a continuous variable, and therefore a defined cutoff value, as this one recommended by ERS is arbitrary. This criterion for a positive bronchodilator response is an increase in $\mathrm{FEV}_{1}$ of $12 \%$ or more from baseline and that exceeds $200 \mathrm{~mL}$, following a therapeutic inhaled dose (200 $\mu \mathrm{g}$ ) of a short acting $\beta_{2}$-agonist (salbutamol). ${ }^{28}$ Before the test, 
short acting bronchodilators (salbutamol and ipratropium bromide) should be withheld for 8 hours and long acting bronchodilators (salmeterol, formoterol, and tiotropium bromide) for 24 hours or longer. ${ }^{28}$

To test direct bronchial responsiveness, since the 1970s, Juniper et $\mathrm{al}^{61}$ introduced the use of inhaled histamine or methacholine. Then cutoff points were chosen on the basis of specificity, rather than sensitivity to methacholine challenges, to identify people with asthma. Different cutoff levels of methacholine or histamine challenges were used for athletes not treated by inhaled corticosteroids (a provocative concentration causing a $20 \%$ fall in $\mathrm{FEV}_{1}\left[\mathrm{PC}_{20}\right]<4 \mathrm{mg} /$ $\mathrm{mL}$ or a provocative dose that decreases the $\mathrm{FEV}_{1}$ by $20 \%$ $\left.\left[\mathrm{PD}_{20}\right] \leq 2 \mu \mathrm{mol}\right)$ and for athletes who have received inhaled corticosteroids for a period $>3$ months $\left(\mathrm{PC}_{20} \leq 6.6 \mathrm{mg} /\right.$ $\mathrm{mL}$ or $\left.\mathrm{PD}_{20} \leq 13.6 \mu \mathrm{mol}\right)$ to obtain approval to use inhaled $\beta_{2}$-agonists. Direct challenge tests are not recommended in athletes with pure EIB because they have been shown to have high specificity but only a low sensitivity for EIB. ${ }^{58}$

Finally, we can test bronchial responsiveness by indirect challenges. Hyperresponsiveness to indirect stimuli, such as exercise and EVH, hypo- or hypertonic aerosols, adenosine 5 '-monophosphate, and a dry powder preparation of mannitol is considered to be more specific for asthma than hyperresponsiveness to a direct stimulus.

Among indirect challenges, currently the EVH test is the recommended challenge test by the IOC, as it is considered the appropriate laboratory based challenge test for the establishment of EIB. This challenge test has been recognized to have both a high sensitivity and specificity for EIB. ${ }^{60}$ In the protocol, the subject is required to perform hyperpnoea by inhaling dry air containing $5 \% \mathrm{CO}_{2}$ (to prevent hypocapnia) at room temperature for 6 minutes at a ventilation corresponding to 30 times baseline $\mathrm{FEV}_{1}$. Maximal voluntary flow volume loops are measured before EVH (best of three) and at 3, 5, 10, and 15 minutes after stopping hyperventilation. ${ }^{62}$ Actually, the osmotic challenge tests, such as the hypertonic saline and inhaled dry powder mannitol, have been shown to have both a high sensitivity and specificity for EIB and may be a useful alternative to the EVH challenge. ${ }^{39}$

A reduction in $\mathrm{FEV}_{1}$ of $10 \%$ before and after the provocative agent for indirect tests, except for mannitol, is considered adequate and comparable with the stimulus of the standardized exercise test. ${ }^{62}$ Mannitol is given by inhalation in progressively increasing doses where the dose inhaled should be $\leq 635 \mathrm{mg}$ to cause a decrease in $\mathrm{FEV}_{1}$ of $15 \%$. $^{63}$ Finally, we must remember that, unlike in sedentary subjects,
$\mathrm{F}_{\mathrm{E}} \mathrm{NO}$ is a poor predictor of BHR and of clinical asthma in elite athletes. ${ }^{64}$

\section{EFL}

EFL in nonasthmatic athletes is a common finding during exercise when higher ventilatory requirements, determined by either larger tidal volume (with similar respiratory rate and expiratory time) or faster respiratory rate and shorter expiratory time (with similar tidal volume), or both, produce an increased mean tidal expiratory flow and reduced expiratory flow reserve during tidal breathing, ${ }^{65}$ so that ventilator capacities are no longer able to meet the higher metabolic demands.

EFL represents a cause of ventilatory limitation to maximal exercise in highly trained endurance athletes and can be a cause of hypoxemia on exertion. ${ }^{6,8,40,66}$ It is a phenomenon more frequent in females because of their reduced airway caliber. ${ }^{7,8}$ Even body position, aging, hyperpnea-tachypnea, exercise, low volume breathing, or airflow reduction, alone or more often combined, are the main elements involved in the development of EFL in humans. ${ }^{65}$

Most of the mechanical constraint over minute ventilation (VE) has a functional origin because of the upper limit to flow rate exerted by the airways, especially during expiration, manifested by the maximal volitional FVL envelope. Partial encroachment of the tidal volume loop over the maximum FVL can be evident in most of the trained subjects during high levels of exercise. ${ }^{65}$ In several fit young men and especially in women and older fit adults, ${ }^{7,8}$ tidal breathing during maximal exercise achieves both high flow rate and large volumes so that the whole area of the maximum volitional FVL can be covered. ${ }^{65}$ Because of the increased ventilatory requirements determined by the metabolic needs during maximum exercise, these groups are especially liable to expiratory flow limitation, not only in cases of normal maximum FVL in young males, but mainly when dealing with smaller FVL recorded in females (compared to males of similar anthropometric size). There is also a significant age dependent reduction in lung elastic recoil and expiratory flow reserve observed in the older endurance athletes ( 65 to 75 years old). Maximal FVLs should be recorded every 2 minutes during exercise and recovery phases of an incremental maximal cardiorespiratory test. ${ }^{67}$

Hyperinflation and reduced inspiratory capacity accompany EFL. Hyperinflation allows further increases in expiratory flow rate and $\mathrm{VE}$, but with some costs to be paid. ${ }^{6-8}$ Dyspnea is increased because of the increased elastic work of breathing for the reduced dynamic lung compliance and 
of inspiratory muscle fatigue exacerbation (these muscles have to work at a shorter than optimal length and a higher velocity of shortening). Furthermore, tidal volume (VT) reaches an early plateau, and respiratory rate has to rapidly increase. ${ }^{6-8}$ Finally, hyperinflation increases left ventricle after load with compromise of cardiac output by a positive expiratory intrapleural pressure. ${ }^{68}$

That flow limitation may constrain VE has been experimentally documented by the increase in VT and VE with concurrent reduction in the end-expiratory lung volume, and in the ventilatory response to $\mathrm{CO}_{2}$ occurring when low density $\mathrm{He}-\mathrm{O}_{2}$ mixtures are inspired to allow a greater expansion of the maximum FVL and to remove expiratory flow limitation. ${ }^{66}$ In the same study, it has been suggested that less than $50 \%$ of the tidal volume is needed to encroach on the maximum expiratory FVL, before the rise of end-expiratory lung volume can be observed and VT and VE be constrained. Apparently, this phenomenon has been observed when tidal breathing envelopes impinge on or are even greater than the inner edges of maximal volitional FVLs recorded at regular intervals during exercise and in the recovery phase. ${ }^{66}$ Because of technical artifacts due to thoracic gas compression occurring during forced maneuvers and to the consecutive emptying of the lungs regions with unequal time constant and time/ volume history in the preceding inspiration, this method has not been truly reliable. To overcome these limitations in the detection of EFL, the negative expiratory pressure (NEP) method has been implemented in the research and clinical practice. ${ }^{69}$ A negative pressure of a few $\mathrm{cm} \mathrm{H}_{2} \mathrm{O}$ (no more than $5 \mathrm{~cm} \mathrm{H}_{2} \mathrm{O}$ ) is administered to the mouth at the beginning of expiration to settle a pressure gradient between the alveoli and airway opening. NEP applied for the whole expiration will ascertain a rise of expiratory flow in the absence of EFL. On the contrary, the expiratory flow does not grow in extent over the flow of the preceding control expiration, entirely or partially over the tidal expiration, in the presence of total or partial EFL (Figure 2). The NEP method that has been verified by means of isovolume pressure flow curves is not dependent on the cooperation of the subjects and does not require body plethysmography; consequently it can be
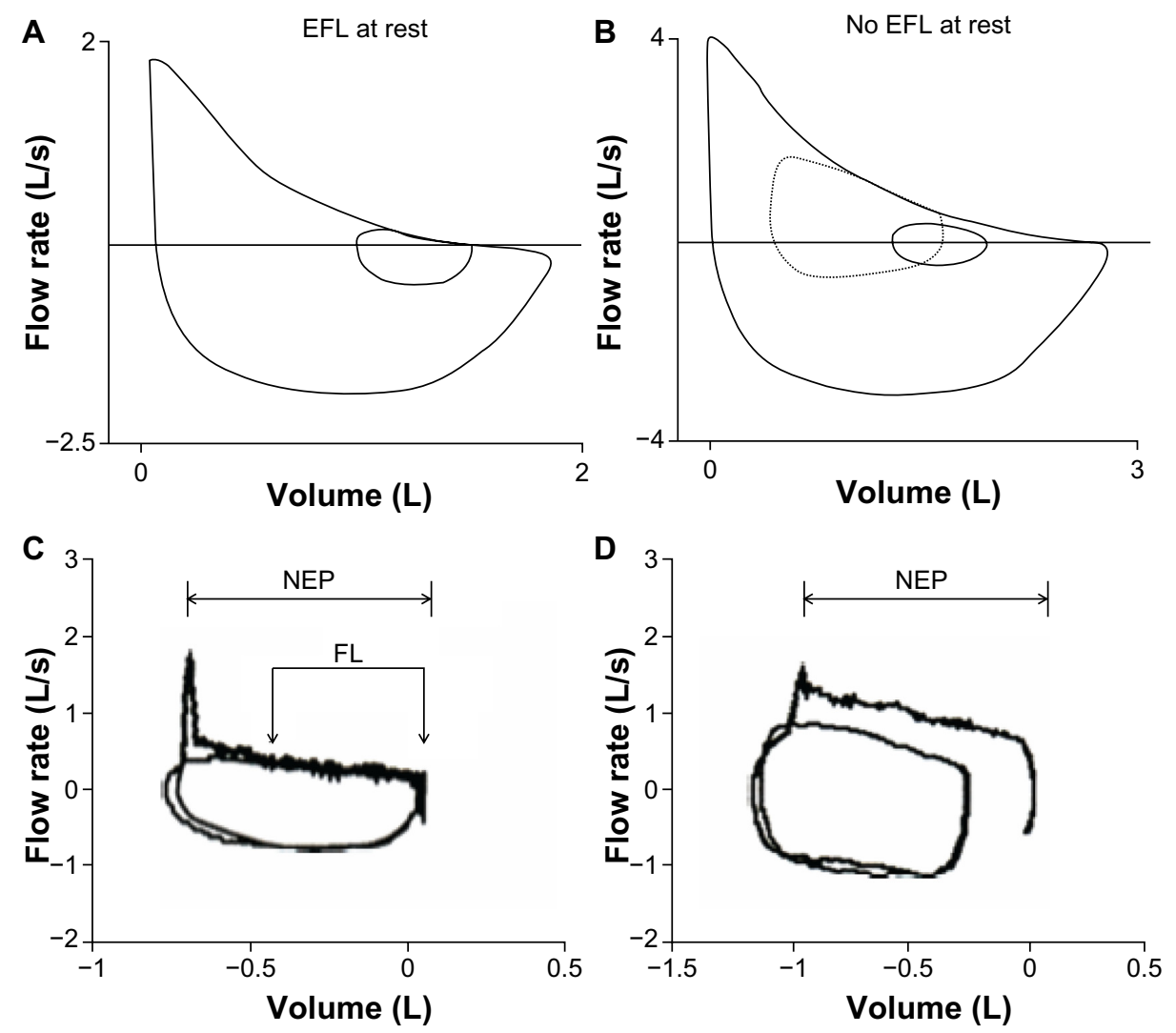

Figure 2 Maximal and tidal flow volume curves in two chronic obstructive pulmonary disorder patients.

Notes: (A) The first with tidal expiratory flow limitation (EFL) at rest. (B) Airflow reduction at rest but no EFL. (C) The negative expiratory pressure application does not increase expiratory flow in the first patient. (D) The negative expiratory pressure application elicits greater expiratory flow. Reproduced from Tantucci C. Expiratory flow limitation definition, mechanisms, methods, and significance. Pulm Med. 20I3;20I3:749860. ${ }^{65}$ Copyright @ 2013 Claudio Tantucci. This is an open access article distributed under the Creative Commons Attribution License, which permits unrestricted use, distribution, and reproduction in any medium, provided the original work is properly cited. Abbreviations: EFL, expiratory flow limitation; NEP, negative expiratory pressure. 
performed at rest in any body position or even during effort and is usually free from interpretative mistakes. ${ }^{69}$

Recently, the use of forced oscillation technique (FOT) during tidal breathing has been of help to detect EFL breathby-breath, both at rest and during exercise. ${ }^{70}$ In FOT an oscillatory pressure is applied to the mouth. If the oscillatory pressure does not reach the alveoli during expiration because of the presence of a flow limiting segment in the bronchial tree, the subsequent reflexed signal of reactance, instead of being determined by the mechanical properties of both lung parenchyma and airways, is elicited only by those of the airways. In this case, the reactance signal becomes a lot more negative than usual with a clear within-breath distinction between inspiration and expiration. FOT is a promising diagnostic tool to identify EFL during tidal breathing.

\section{Upper airway obstruction such as VCD or laryngomalacia}

Obstruction of the upper airways can be characterized by shortness of breath, increased inspiratory effort, stridor, and wheeze. Upper airway obstruction may be dynamic and only present during exercise. ${ }^{9}$ The most common cause of upper airway obstruction during exercise is VCD, a paradoxical vocal cord movement. In some subjects, during inspiration the vocal cords are not abducted (open) but paradoxically adducted (close) even in the early expiration which causes obstruction. In patients with exercise-induced dyspnea, the prevalence of VCD has been reported to range from $5 \%$ to $15 \% .^{10}$

Diagnosis of VCD has been associated with gastroesophageal reflux and type A personalities, and it should be suspected with a history of inspiratory wheeze and throat tightness. VCD appears to be prevalent among young females. The diagnosis of VCD is suspected by FVL with variable blunting of the inspiratory loop sometimes developed after methacholine challenge test. ${ }^{39}$ The inspiratory closure with posterior "chinking" (a limited opening at the posterior aspect of the cords) or, less commonly, a complete closure of the vocal cords, are the typical findings from laryngoscopy. The paradoxical motion of the vocal cords revealed by the fiberoptic rhinolaryngoscopy, or better by continuous laryngoscopy during an exercise test, ${ }^{71}$ allows the definitive diagnosis of VCD. VCD may be responsive to breathing retraining by rehearsing cycles of conscious diaphragmatic breathing and relaxation of the larynx. Speech pathologists play a key role in instructing subjects in the breathing training exercises. ${ }^{9}$

Laryngomalacia is a less common cause of exerciseinduced stridor. It is prevalent in female competitive athletes who suddenly develop stridor at near peak exercise. The larynx in females may be susceptible to collapse because of its shortness and narrowness in comparison to males. ${ }^{9}$ It is differentiated from VCD by fiberoptic rhinolaryngoscopy. Collapse of the arytenoid area with normal vocal cord motion is the distinctive finding, and laser supraglottoplasty has been a successful treatment. ${ }^{9}$

\section{$\mathrm{EIAH}$}

EIAH is characterized by a substantial exercise-induced arterial $\mathrm{O}_{2}$ desaturation during the last part of excessive exercise. Estimated noninvasively via pulse oximetry, EIAH is very frequent. ${ }^{2,40,41}$ We have already seen that EIAH can be recognized by a long series of causes among which we must remember interstitial pulmonary edema, small intracardiac or intrapulmonary shunts patency, ${ }^{11,12}$ the occurrence of inadequate hyperventilation due to a mechanical constraint by expiratory flow limitation, ${ }^{66}$ or to blunted chemoreceptor sensitivity. ${ }^{72}$ Most of these clinical aspects can be detected in the laboratory or in the field by diagnostic tools of different complexity.

The significance of the desaturation phenomena during an excessive effort is unclear: in other terms should we consider these phenomena as the ultimate extent of human $\mathrm{O}_{2}$ transport capability, ie, a nearly physiologic response, or alternatively an abnormality of the respiratory function causing limitation of endurance performance?

\section{Interstitial PE}

Isolated cases of $\mathrm{PE}$ occurring in athletes after strong exercise have been anecdotally reported in literature. ${ }^{23-25}$ Overt PE is fortunately a rare, dramatic clinical event characterized by dyspnea, cough, hemoptoe, and EIAH is much more frequent and normally totally asymptomatic. ${ }^{13}$ Among the causes of EIAH, there is an excessive increase during exercise of the alveolar-capillary gradient for $\mathrm{O}_{2}$ tension $\left(\Delta \mathrm{P}_{\mathrm{A}-\mathrm{a}} \mathrm{O}_{2}\right)$ difference related to a ventilation/perfusion inequality, at least in part dependent from interstitial pulmonary edema formation. ${ }^{40}$

It has been postulated that the first step in this series of events is an excessive increase in blood flow through the pulmonary capillary bed. When complete recruitment of the capillary bed is achieved, the pressure in precapillary vessels rises, causing excessive wall stress, that translates into a failure of the normal properties of the alveolar-capillary membrane and fluid transudation. ${ }^{73,74}$

An alveolar PE can easily be diagnosed. More difficult is recognizing the formation of interstitial edema. ${ }^{13}$ However, detection of increased closing lung volume and/or reduction 
in diffusing capacity test provides a clue of early small airway compression due to pulmonary interstitial fluid accumulation/edema. ${ }^{75}$ Revealing an early phase of PE is fundamental, because the increased pulmonary extravascular fluid would exert an early compression of the airways having the effect, at rest, of an increased volume at which small airways close and later on, during exercise, of a functional sever of lung volume that diminishes maximal expiratory flow rates at tidal volume. Based on Guy's single breath techniques, this method does not require foreign inert gases or $100 \%$ of oxygen and can be applied by measuring closing volume with hand portable equipment directly in the field. ${ }^{76}$

An additional functional method that gives the opportunity to test the alveolar-capillary membrane integrity is the lung diffusing capacity test. ${ }^{77}$ In particular, the lung diffusion for carbon monoxide (DLCO) is the expression of the carbon monoxide $(\mathrm{CO})$ passage through the alveolar-capillary membrane and into the plasma and the erythrocytes. Persistent reduction of DLCO is expected in the case of thickening of the alveolar-capillary wall, as in the presence of interstitial edema. ${ }^{77}$

Many studies demonstrated a decreasing of DLCO in endurance athletes after a strong and prolonged exercise: some of these, to reinforce the hypothesis of the formation of interstitial edema even in apparently healthy subjects, have combined the DLCO measurement with radiological techniques, such as $\mathrm{MR}^{78}$ and computed tomography (CT). ${ }^{79}$

Imaging radiological techniques, such as $\mathrm{CT}$, MR, and chest radiography, ${ }^{80}$ are equally reliable in supporting the diagnosis of interstitial edema induced by exhausting endurance sports. These findings sustain the concept of a heterogeneous distribution of elevated capillary pressures related to the development of a heterogeneous distribution of hypoxic vasoconstriction in either pulmonary arteries or veins, or both. ${ }^{73} \mathrm{MR}$ provides information regarding tissue abnormalities (ie, the presence of interstitial edema), the exercise-induced changes in ventilation distribution, and by means of arterial spin labeling, measures of pulmonary perfusion which are also evidence of the incidence of ventiloperfusive mismatch. Obviously, the high accuracy of CT and MR in detecting PE is negatively affected by a series of limiting conditions (costs, availability, complexity, duration, and, only for $\mathrm{CT}$, ionizing exposure), which prohibits routine use in healthy subjects on the field.

Vice versa, chest ultrasonography is a nonionizing, noninvasive imaging technique, easily available and suitable in relation to its low time consuming application, sustainable cost, and high versatility. The ultrasound comet tail image is a pathognomonic echographic sign resembling multiple comet tails spreading out from the lung surface. ${ }^{81}$ This particular image arising from water thickened interlobular septa may give an approximate, semiquantitative hint for estimating extravascular lung water excess and indirectly pulmonary wedge pressure, and it is also sensitive and accurate for detection of early subclinical interstitial edema. Chest ultrasound scanning is hand portable and examinations directly in the field are allowed. A study, realized on ultratriathlon athletes at the end of an exhaustive exercise, documented a significant increase in ultrasound comet tail image that partially faded after 12 hours. $^{82}$

\section{Intracardiac or intrapulmonary shunts}

During exercise the opening of two types of shunts, intracardiac and/or intrapulmonary, has been demonstrated. A patent foramen ovale has been recognized as a potential intracardiac shunt in $20 \%-25 \%$ of the general population. ${ }^{83}$ However, the patency of the shunts during exercise will be resultant from the gradient of pressures manifested between the right and left atrium. As the pressure difference is normally negative during exercise, the higher left atrial pressure would determine closure of the flap valve against the septum secunda, thereby impeding the right-to-left venous blending. Nonetheless, considerable right-to-left intracardiac shunting has been evidenced under effort in the presence of pulmonary hypertension and in hypoxic conditions. ${ }^{84}$

Intrapulmonary arteriovenous shunt pathways $>50 \mu \mathrm{m}$ diameter develop when physiologic perfusion pressures are applied to isolated human lungs. In the past few years, evidence for the recruitment of intrapulmonary arteriovenous shunt pathways during exercise in healthy subjects with no demonstration of an intrapulmonary or intracardiac shunt at rest, has been collected. ${ }^{11}$ Arteriovenous shunt pathways, occurring both at rest and with exercise, ${ }^{12}$ may be sensitively ascertained by using echocardiography with a saline solution contrast medium shaken to create bubbles before being injected into a peripheral vein. Saline solution contrast echocardiography is regarded as the most sensitive and reliable method for detecting arteriovenous shunt pathways and allowing the differential diagnosis between intracardiac from intrapulmonary shunting. ${ }^{11}$

\section{Preclinical screening methods}

Respiratory disorders in the athletic population are the cause of increased morbidity, a worsening of sport performance, and in rare cases of sudden death. Consequently, the need to dispense a widespread screening program, similar to those 
arranged for cardiovascular diseases, has been considered necessary. Notably, any preventive action should take into consideration not only an individual's features, but even the environmental conditions (altitude, temperature, exposure to air allergens, etc) in which the athletes usually perform.

In athletes known to be atopic, repeated airway injury is thought to create a sensitization of the bronchial smooth muscle and an increased risk of BHR and EIA. ${ }^{85}$

But if long term (along several years) endurance training can be the cause of development of airflow limitation, ${ }^{86}$ there is also evidence that the interruption of sporting activity may block this pathological progression in the airways. ${ }^{87}$

On the other hand, it has also been supposed that more transient airway changes can have a seasonal pattern as noted, eg, in elite Finnish runners. ${ }^{88}$

Consequently, not only atopic athletes should be studied for EIB/BHR, but preventive measures should be adopted for athletes known to be sensitized to avoid the detrimental effects due to training in environments with high levels of airborne allergens.

For example, endurance trained athletes of Mediterranean regions are never subject to very cold and dry weather, but they are normally challenged by a considerable release of airborne allergens, often occurring at the beginning of spring, and/or exposure to ozone (by the photochemical forming reactions) during hot summer days. At the same time, the training workload becomes gradually more intensive, from the low burden during the basal training period (fall/winter) to the high levels during the precompetitive (winter/spring) and competitive (summer) season. As hyperventilation would be more common and longer when the quality of the ambient air is worsened (allergens and ozone concentrations peak), impairment of lung function in these athletes could be expected in the course of the season.

However, a study planned by Kippelen et al ${ }^{89}$ failed to show significant evidence of lung function impairment in endurance trained athletes after 1 year of training in the Mediterranean area. Ventilatory response to exercise and single breath $\mathrm{O}_{2}$ test were examined three times, along with lung function before and after exercise, with only minor and nonclinically significant changes noticed through the season. Moreover, a change in the breathing pattern was also observed during maximal exercise performed in the competitive period (a changeover to a fast and shallow breathing) inferring that the ventilatory adjustment was no longer comparable at the end of the sports season, because of an increased exposure to a polluted environment (increased ambient ozone) or, more probably, of respiratory muscle fatigue development. ${ }^{89}$
Also, another study on Tunisian runners failed to show any deterioration in symptoms or changes in pulmonary function after 1 year of training, even in the face of increased markers of inflammation..$^{90}$

Currently, it is not possible to foresee when a nonasthmatic endurance athlete may experience significant bronchospasm during exercise. Therefore, qualified health care personnel are an invaluable resource to manage such episodes when they unexpectedly occur. As previously stated in the diagnostic testing section, history and physical examination alone are not trustworthy in detecting the presence or absence of EIB/BHR, also because there are several disorders that can simulate EIB. The situation is often unclear, and this is confirmed by the fact that roughly half of those athletes suffering from EIB-like symptoms have airway function at rest in the normal range, while half of those who are asymptomatic will manifest bronchospasm after exercise or other indirect challenge..$^{91}$

Because of relatively high prevalence of EIB in elite level athletes, some organizations have been implementing specific screening tests for athletes..$^{92}$ No current guidelines are provided to plan this practice and its efficacy and cost effectiveness is controversial. These screening activities should be aimed at the recognition of asthmatic patients A proper diagnosis would have a dual purpose: to allow asthmatic athletes to be treated according to the present guidelines, also when participating in sports, and to avoid treatment of subjects with similar symptoms but different diagnoses. ${ }^{93}$ There now exists overwhelming evidence that inhaled $\beta_{2}$-agonists ${ }^{93,94}$ and inhaled corticosteroids ${ }^{95}$ do not improve performance in healthy athletes, and that paradoxically, an erroneous or even excessive treatment can exacerbate asthma episodes. ${ }^{93}$ This favors an approach which should give priority to sensitivity over specificity in the use of laboratory methods as a tool in documenting the diagnosis of asthma. Before settling on widespread screening for EIB, the assessment of the potential benefits and harm in testing the endurance athletes, at least winter athletes and swimmers who are at more risk, is needed. ${ }^{92}$

Many public institutions have established guidelines, valid at a national level, on the screening test to be applied to many sports athletes. The Italian Ministry of Health for example, since 1982, has drawn up standards of health protection in competitive sports where spirometry has been inserted between screening tests for all aerobic sports activities of medium and high level. ${ }^{96}$ Furthermore, as we have already described, the IOC-MC required that all athletes using inhaled $\beta_{2}$-agonists participating in winter and summer 
Olympic Games produce objective evidence of EIB, making the bronchial provocation challenge tests necessary in the diagnosis of EIB. ${ }^{54}$

\section{Nonpharmacologic treatment}

Even if the treatment of athletes with EIB is pharmacologic, alternative measures, including preventing strategies, have been found to be efficacious despite the lack of studies comparing the nonpharmacologic treatments with medication. Strategies to lower the impact of environmental factors on exercise-induced airway injury in elite athletes take into account specific noxious agents, such as 1) cold air for winter sports athletes, 2) byproducts of chlorination for swimmers, 3) airborne pollutants, 4) airborne allergens for atopic subjects, and 5) respiratory tract infections. The most common nonpharmacologic preventive strategies together with some recommended ways of practicing exercise are included in this paragraph. Preventive measures to mitigate the dehydration-induced airway injury in the field by the achievement of an increasing water content of the air inspired has been put into action either naturally (ie, by raising water content/absolute humidity), through nasal breathing, or by putting heat and moisture exchange (HME) devices to use (either as a simple face mask or as a mouthpiece to heat exchange devices). ${ }^{97}$ The latter ones are more suitable because nasal breathing is unattainable when the breathing changeover from nasal to oronasal usually occurs at ventilation exceeding approximately $35 \mathrm{~L} / \mathrm{min}$. For this reason, the use of HME devices can be the only individual approach left to cold weather athletes to impede airway dehydration and heat/ water loss by the increase of the inspired air temperature from minus $10^{\circ} \mathrm{C}$ to at least $19^{\circ} \mathrm{C}$. The protective effect against EIB provided by HME devices can enhance the favorable effects of $\beta_{2}$-agonists, ${ }^{98}$ and this has been shown as considerable, especially during training at low and subfreezing ambient temperatures. Both the increased airway resistance and dead space are the major inconveniences of HME that makes it impractical to train intensively for long periods or during competitions. $^{97}$

Control of the environment, by fixing suitable thresholds in which the athletes train and compete, is another significant preventive measure. The medical advisor's recommendations, edited by the Federation Internationale de Ski's website, define the lower limits of ambient temperature for cross-country skiing (ie, $-16^{\circ} \mathrm{C}$ for races $30 \mathrm{~km}$ or longer, $-18^{\circ} \mathrm{C}$ for shorter distance races, $-20^{\circ} \mathrm{C}$ for sprint races, and biathlon competitions not authorized in cases of air temperature below $-20^{\circ} \mathrm{C}$ ) and when implemented would be beneficial in reducing airway injury in competitive cold weather athletes. ${ }^{97}$

Chlorine containing agents reacting with organic nitrogen containing compounds (eg, sweat, dirt, and urine), scattered by users into the pool, lead to the formation of various well known irritant byproducts, particularly chloramine, such as nitrogen trichloride, that can cause acute disarray of the airway epithelium..$^{99}$ A concentration of nitrogen trichloride below $0.3 \mathrm{mg} / \mathrm{m}^{3}$ has been advised as not detrimental to lung function or airway epithelial permeability of swimmers in the short term. As elite swimmers and synchronized swimmers are recommended not to stay in a chlorinated atmosphere even during out-of-water training, satisfactory ventilation (ie, fresh air flow rate not less than $60 \mathrm{~m}^{3} /$ hour) should be maintained to reduce the concentration of chloramines gathered in the air above the pool water. ${ }^{99}$

Polluted air, especially freshly generated particular matter (PM) from combustion engines, has been shown to be highly injurious to the airways, especially when high ventilation during strenuous exercise develops in areas where PM levels exceed the standards set by Environmental Protection Authorities. In these circumstances, a greater deposition of $\mathrm{PM}$ in the lungs and a higher concentration of ozone $\left(\mathrm{O}_{3}\right)$ and mono-nitrogen oxides $\left(\mathrm{NO}_{x}\right)$ entering the airways increase the risk of airway injury. ${ }^{100}$

Indoor air quality in ice skating arenas, with regard to the levels of NOX and the particulate matter with aerodynamic diameter 0.02-1 $\mu \mathrm{m}$ (PM1), is improved by increasing ventilation to mitigate airway injury and inflammation in ice hockey players and in speed and figure skaters. Fumes from fluorinated ski waxes originating from daily hot waxing are another cause of airway injury in Nordic and alpine skiers; they are exposed even at rest and on a daily basis since the early phases of their career. ${ }^{101}$ Similar to other cases, this is also a case where adequate ventilation of indoor air is a beneficial preventive measure.

Atopic athletes are thought to have an enhanced risk for BHR. Consequently, athletes with known allergies/ rhinitis should plan to train in environments with low levels of airborne allergens. ${ }^{101}$ Similarly, respiratory tract infections, such as the common cold, increase the burden of the airway epithelium to injuries: athletes should be careful to withdraw contact with subjects showing signs of upper airway infections. For asthmatic athletes, annual influenza vaccination should be considered ${ }^{85}$ The threshold at which symptoms of EIB develop is usually raised, and the severity of EIB is simultaneously diminished, by the improvement of conditioning and the practice of warm up ${ }^{102,103}$ and inter- 
mittent exercises. ${ }^{104,105}$ The beneficial effects are related to the enhancement of bronchial blood flow and to a higher rate of water returned to the airway surface, and may not only extinguish EIB but also lead to short term resistance to EIB. ${ }^{85}$

Furthermore, physical training increases maximal exercise capacity and delays anaerobic threshold. Consequently, compensatory hyperpnoea, one of the major stimuli for EIB, is delayed and exercise tolerance improves after aerobic training. Respiratory muscle training may also improve exercise capacity improving asthma symptoms.

\section{Pharmacologic treatment}

Drug treatment of respiratory disorders in elite athletes should follow standard national or international guidelines (eg, Global Initiative for Asthma), ${ }^{106}$ be individualized to achieve control, be monitored, and eventually must comply with current restrictions by sports' governing bodies (eg, World Anti-Doping Agency [WADA]). ${ }^{107}$ According to the IOC Consensus Statement on Asthma in Elite Athletes (January 2008), inhaled corticosteroids are considered as the most effective drugs for long term control of asthma and prevention of EIB. ${ }^{108,109}$

Instead, $\beta$-adrenergic agonists, short acting inhaled $\beta$-adrenergic agonists (SABAs) and long acting $\beta$-adrenergic agonists (LABAs), are the most commonly recommended, are generally well tolerated, and are effective medications for the immediate inhibition of EIB and for relieving intermittent symptoms of asthma..$^{93,110}$

However, either the common side effects including tachycardia, palpitations, and anxiety, or frequent use causing rapid tolerance (or tachyphylaxis) will partially reduce the effectiveness of $\beta$-adrenergic agonists in preventing EIB. Consequently, infrequent use of $\beta_{2}$-agonists has been recommended together with the use of alternative treatments to prevent EIB. ${ }^{54,93}$ Because there is now sufficient evidence in the literature indicating that both inhaled steroid and SABAs and LABAs do not improve athletic performance in healthy athletes, ${ }^{93-95} \beta_{2}$-agonists are also regularly used in addition to inhaled steroids.

Article 4.2.2 of the World Anti-Doping Code refers to the Prohibited List as the international standard. ${ }^{107}$ This list, which has just come into force on January 1, 2014, stipulates that all $\beta_{2}$-agonists including their D-and L-isomers are prohibited at all times (in and out of competition). Their use requires a Therapeutic Use Exemption. As an exception, formoterol (maximum $54 \mu \mathrm{g}$ over 24 hours), salbutamol (maximum 1,600 $\mu \mathrm{g}$ over 24 hours), and salmeterol (when taken by inhalation in accordance with the manufacturers' recommended therapeutic regime), when administered by inhalation to prevent and/or treat asthma and exerciseinduced asthma/bronchoconstriction, are permitted. ${ }^{107}$ This is required by the WADA, which is the controller organ of all international competitive sports, except for the Olympic Games that are under the control of the IOC-MC. As we have already seen, the IOC-MC required an objective documentation of BHR or EIB to permit the use of $\beta_{2}$-agonists.

Even if $\beta_{2}$-agonists are likely to be recognized as the most effective bronchodilators available in the near future, a second line medication, rarely used as monotherapy in practice, is a group of leukotriene antagonists which is considered as effective as LABAs so that its use should achieve better management of EIB, as stated in the IOC Consensus Statement on Asthma in Elite Athletes. ${ }^{54,55}$ Consequently, $\beta_{2}$-agonist use would be helpful only for occasional or symptomatic use. Leukotriene antagonists may be helpful in the treatment of EIA and have been shown to be more effective in the EIB that is refractory to $\beta$-adrenergic agonists. However, the beneficial effects of montelukast in athletes with EIB or asthma are uncertain, even though it has been shown to be particularly effective in limiting bronchoconstriction in a population exposed to the inhalation of ice rink air containing high concentrations of PM1. ${ }^{11}$ This is a further clue that bronchoconstriction and the underlying airway injury may be the result of a leukotriene mediated pathogenetic process. An adjunctive treatment for EIA is cromolyn sodium. ${ }^{112}$ The altered ventilation and/or perfusion distribution has commonly been attributed to an increased concentration of some airway or vascular tone mediators such as histamine. This observation has also been suggested by the improvement in impaired gas exchange with the use of nedocromil sodium in athletes with EIA. ${ }^{112}$ With atopy being a risk factor for the worsening of EIA or development of BHR in elite athletes, antihistamines and intranasal steroids are usually prescribed for seasonal allergies and allergic rhinitis to achieve a reduction of the allergic airway inflammation. Leukotriene antagonists, antihistamines, and cromolyn sodium are allowed substances by sports' governing bodies. ${ }^{107}$ Because pollutant induced bronchoconstriction is usually mediated by the oxidative stress, an accessory short term antioxidant supplementation (vitamins $\mathrm{C}$ and $\mathrm{E}$ ) together with a low salt diet has been recommended to athletes exposed to air pollutants, even though the long term effects (beneficial or detrimental) of their chronic use on the respiratory health of athletes are unknown. ${ }^{113}$ Also, omega-3 polyunsaturated fatty acids decrease inflammatory eicosanoids, cytokines, and reactive 
oxygen species levels, with a small but significant improvement in $\mathrm{FEV}_{1}$ in asthmatic adults taking a low dose of fish oil ( $1 \mathrm{~g} /$ day of eicosapentaenoic acid and docosahexaenoic acid) for 12 months. ${ }^{114}$ In summary, both the implementation of prevention strategies for inhibiting acute airway injury and the efficacy of various pharmacological agents for reducing the risk for long term development of airway impairment in elite athletes needs experimental validation through the planning of longitudinal studies of efficacy.

\section{Conclusion and future direction}

With the state of current knowledge, cardiac problems are not the only cause of morbidity and mortality among endurance athletes. For this reason, the abovementioned meaningful evidence of respiratory disorders in endurance athletes deserves to be widespread knowledge both in the scientific and in the athletic international community. As a matter of fact, paying attention to the concept that the respiratory system may show a pathophysiological limitation to endurance performance and sometimes be a cause of illness or even death is definitely the first step.

Consequently, priority is given to the screening plans for atopic athletes and those athletes engaged in extreme aerobic disciplines, because of both the high intensity of the demanded effort and/or unfavorable environmental conditions in which they are challenged.

Screening activities may include simple to administer respiratory testing, such as the EVH challenge, or more sophisticated and comprehensive tests such as a maximal cardiopulmonary exercise test with FVL, to assess the presence of the phenomena of bronchospasm and/or desaturation during strenuous effort. The development of protocols for studies in which these tests can be executed in environmental conditions as similar as possible to those in which the competition takes place will produce more accurate and predictive results and, in addition, will considerably improve the screening activity. The possibility of realizing diagnostic tools that are even smaller and more easily portable in the field will allow rapid achievement of this goal.

As has occurred in the context of rehabilitation, where specific training protocols have proven efficacy as an auxiliary therapy for chronic respiratory diseases, we believe that the right balance between drug therapy and training mode will also somehow represent a new approach to respiratory disorders of endurance athletes.

In conclusion, taking up the question of the title of this report, we can say that every endurance athlete has their own limit in endurance training that once passed will produce all the possible respiratory disorders previously described. The question is precisely to understand if there is a limit in terms of intensity and/or in terms of duration in years to endurance training, before respiratory disorders can appear, and if we can apply any preventive strategies. To be an endurance champion, this inevitably means accepting all the labors of strong training but also enduring all possible health problems caused by the same.

\section{Disclosure}

The authors report no conflict of interest in this work.

\section{References}

1. Mahler DA, Loke J. Lung function after marathon running at warm and cold ambient temperatures. Am Rev Respir Dis. 1981;124:154-157.

2. Dempsey JA, Hanson PG, Henderson KS. Exercise-induced arterial hypoxaemia in healthy human subjects at sea level. J Physiol. 1984;355: 161-175.

3. West JB. High-altitude medicine. Am J Respir Crit Care Med. 2012;186:1229-1237.

4. Bolton JW, Weiman DS. Physiology of lung resection. Clin Chest Med. 1993;14:293-303.

5. Wagner PD. Why doesn't exercise grow the lungs when other factors do? Exerc Sport Sci Rev. 2005;33:3-8.

6. Johnson BD, Saupe KW, Dempsey JA. Mechanical constraints on exercise hyperpnea in endurance athletes. J Appl Physiol (1985). 1992;73: 874-886.

7. McClaran SR, Harms CA, Pegelow DF, Dempsey JA. Smaller lungs in women affect exercise hyperpnea. J Appl Physiol (1985). 1998;84:1872-1881.

8. Guenette JA, Witt JD, McKenzie DC, Road JD, Sheel AW. Respiratory mechanics during exercise in endurance-trained men and women. J Physiol. 2007;581:1309-1322.

9. Rundell KW, Spiering BA. Inspiratory stridor in elite athletes. Chest. 2003;123:468-474.

10. Nielsen EW, Hull JH, Backer V. High prevalence of exercise-induced laryngeal obstruction in athletes. Med Sci Sports Exerc. 2013;45: 2030-2035.

11. Eldridge MW, Dempsey JA, Haverkamp HC, Lovering AT, Hokanson JS. Exercise induced intrapulmonary arteriovenous shunting in healthy humans. J Appl Physiol (1985). 2004;97:797-805.

12. Stickland MK, Welsh RC, Haykowsky MJ, et al. Intra-pulmonary shunt and pulmonary gas exchange during exercise in humans. $J$ Physiol. 2004;561:321-329.

13. Bussotti M, Di Marco S, Marchese G, Agostoni PG. Subclinical pulmonary edema in endurance athletes. Monaldi Arch Chest Dis. 2012;77:76-82.

14. Cremona G, Asnaghi R, Baderna P, et al. Pulmonary extravascular fluid accumulation in recreational climbers: a prospective study. Lancet. 2002;359:303-309.

15. Harms CA, Babcock MA, McClaran SR, et al. Respiratory muscle work compromises leg blood flow during maximal exercise. J Appl Physiol (1985). 1997;82:1573-1583.

16. Goldstein RS, Hill K, Brooks D, Dolmage TE. Pulmonary rehabilitation: a review of the recent literature. Chest. 2012;142:738-749.

17. Carlsen KH. Sports in extreme conditions: The impact of exercise in cold temperatures on asthma and bronchial hyper-responsiveness in athletes. Br J Sports Med. 2012;46:796-799.

18. Dempsey JA. Is the healthy respiratory system (always) built for exercise? J Physiol. 2006;576:339-340.

19. Maron BJ, Epstein SE, Roberts WC. Causes of sudden death in competitive athletes. J Am Coll Cardiol. 1986;7:204-214.

20. Maron BJ, Doerer JJ, Haas TS, Tierney DM, Mueller FO. Sudden deaths in young competitive athletes: analysis of 1866 deaths in the United States, 1980-2006. Circulation. 2009;119:1085-1092. 
21. Becker JM, Rogers J, Rossini G, Mirchandani H, D’Alonzo GE Jr. Asthma deaths during sports: report of a 7-year experience. J Allergy Clin Immunol. 2004;113:264-267.

22. Casa DJ, Guskiewicz KM, Anderson SA, et al. National athletic trainers' association position statement: preventing sudden death in sports. J Athl Train. 2012;47:96-118.

23. McKechnie JK, Leary WP, Noakes TD, Kallmeyer JC, MacSearraigh ET, Olivier LR. Acute pulmonary oedema in two athletes during a 90-km running race. S Afr Med J. 1979;56:261-265.

24. Young M, Sciurba F, Rinaldo J. Delirium and pulmonary edema after completing a marathon. Am Rev Respir Dis. 1987;136(3):737-739.

25. Boggio-Alarco JL, Jaume-Anselmi F, Ramirez-Rivera J. Acute pulmonary edema during a triathlon occurrence in a trained athlete. Bol Asoc Med P R. 2006;98(2):110-113.

26. Netzer N, Strohl K, Faulhaber M, Gatterer H, Burtscher M. Hypoxia-related altitude illnesses. J Travel Med. 2013;20:247-255.

27. Schommer K, Menold E, Subudhi AW, Bartsch P. Health risk for athletes at moderate altitude and normobaric hypoxia. Br J Sports Med. 2012;46:828-832.

28. Carlsen KH, Anderson SD, Bjermer L, et al. European Respiratory Society, European Academy of Allergy and Clinical Immunology. Exercise-induced asthma, respiratory and allergic disorders in elite athletes: epidemiology, mechanisms and diagnosis: part I of the report from the Joint Task Force of the European Respiratory Society (ERS) and the European Academy of Allergy and Clinic Immunology (EAACI) in cooperation with GA2LEN. Allergy. 2008;63: 387-403.

29. Weiler JM. Exercise-induced asthma: a practical guide to definitions, diagnosis, prevalence, and treatment. Allergy Asthma Proc. 1996;17: 315-325.

30. Anderson SD. Exercise-induced asthma. In: Carlsen KH, Ibsen TB, editors. Exercise-Induced Asthma and Sports in Asthma. Copenhagen: Wiley; 1999:11-15.

31. Weiler J, Bonini S, Coifman R, et al. Ad Hoc Committee of Sports Medicine Committee of American Academy of Allergy, Asthma and Immunology. American Academy of Allergy, Asthma, and Immunology Work Group report: exercise-induced asthma. J Allergy Clin Immunol. 2007;119:1349-1358

32. Moreira A, Delgado L, Carlsen KH. Exercise-induced asthma: why is it so frequent in Olympic athletes? Expert Rev Resp Med. 2011;5:1-3.

33. Fitch KD. An overview of asthma and airway hyper-responsiveness in Olympic athletes. Br J Sports Med. 2012;46:413-416.

34. Dickinson JW, Whyte GP, McConnell AK, Harries MG. Impact of changes in the IOC-MC asthma criteria: a British perspective. Thorax. 2005;60:629-632.

35. Helenius IJ, Rytila P, Metso T, Haahtela T, Venge P, Tikkanen HO. Respiratory symptoms, bronchial responsiveness, and cellular characteristics of induced sputum in elite swimmers. Allergy. 1998;53: 346-352.

36. Karjalainen EM, LaitinenA, Sue-Chu M,AltrajaA, Bjermer L, Laitinen LA Evidence of airway inflammation and remodeling in ski athletes with and without bronchial hyperresponsiveness to methacholine. Am J Respir Crit Care Med. 2000;161:2086-2091.

37. Provost-Craig MA, Arbour KS, Sestili DC, Chabalko JJ, Ekinci E. The incidence of exercise-induced bronchospasm in competitive figure skaters. J Asthma. 1996;33:67-71.

38. Leuppi JD, Kuhn M, Comminot C, Reinhart WH. High prevalence of bronchial hyperresponsiveness and asthma in ice hockey players. Eur Respir J. 1998;12:13-16.

39. Weiss P, Rundell KW. Imitators of exercise-induced bronchoconstriction. Allergy Asthma Clin Immunol. 2009;5:7.

40. Dempsey JA, Wagner PD. Exercise-induced arterial hypoxemia. J Appl Physiol (1985). 1999;87:1997-2006.

41. Harms CA, McClaran SR, Nickele GA, Pegelow DF, Nelson WB, Dempsey JA. Exercise-induced arterial hypoxaemia in healthy young women. J Physiol. 1998;507:619-628 .

42. AdirY, ShupakA, Gil A, et al. Swimming-induced pulmonary edema: clinical presentation and serial lung function. Chest. 2004;126: 394-399.
43. Page CL, Diehl JJ. Upper respiratory tract infections in athletes. Clin Sports Med. 2007;26:345-359.

44. Haahtela T, Malmberg P, Moreira A. Mechanisms of asthma in Olympic athletes-practical implications. Allergy. 2008;63:685-694.

45. Bonini M, Lapucci G, Petrelli G, et al. Predictive value of allergy and pulmonary function tests for the diagnosis of asthma in elite athletes. Allergy. 2007;62:1166-1170.

46. Schwartz LB, Degado L, Craig T, et al. Exercise-induced hypersensitivity syndromes in recreational and competitive athletes: a PRACTALL consensus report (what the general practitioner should know about sports and allergy). Allergy. 2008;63:953-961.

47. Anderson SD, Kippelen P. Airway injury as a mechanism for exerciseinduced bronchoconstriction in elite athletes. J Allergy Clin Immunol. 2008; 122:225-235.

48. Bougault V, Loubaki L, Joubert P, et al. Airway remodeling and inflammation in competitive swimmers training in indoor chlorinated swimming pools. J Allergy Clin Immunol. 2012;129:351-358.

49. Anderson SD, Holzer K. Exercise-induced asthma: is it the right diagnosis in elite athletes? J Allergy Clin Immunol. 2000;106: 419-428.

50. Gilbert IA, McFadden ER Jr. Airway cooling and rewarming. The second reaction sequence in exercise-induced asthma. J Clin Invest. 1992;90:699-704.

51. Sue-Chu M, Brannan JD, Anderson SD, Chew N, Bjermer L. Airway hyperresponsiveness to methacholine, adenosine 5-monophosphate, mannitol, eucapnic voluntary hyperpnoea and field exercise challenge in elite cross-country skiers. Br J Sports Med. 2010;44: $827-832$.

52. Niles DJ, Kruger SJ, Dardzinski BJ, et al. Exercise-induced bronchoconstriction: reproducibility of hyperpolarized $3 \mathrm{He} \mathrm{MR}$ imaging. Radiology. 2013;266:618-625.

53. Rundell K, Slee J. Exercise and other indirect challenges to demonstrate asthma or exercise-induced bronchoconstriction in athletes. J Allergy Clin Immunol. 2008;122:238-246.

54. International Olympic Committee. IOC Consensus Statement on Asthma in Elite Athletes. Lausanne: International Olympic Committee, 2008. Available from: http://www.olympic.org/Documents/Commissions_PDFfiles/Medical_commission/IOC $\% 20$ CONSENSUS $\% 20$ STATEMENT\%20ON\%20ASTHMA\%20IN\%20ELITE\%20 ATHLETES_2008.pdf. Accessed January 13, 2014.

55. Fitch KD, Sue-Chu M, Anderson SD, et al. Asthma and the elite athlete: summary of the International Olympic Committee's consensus conference, Lausanne, Switzerland, January 22-24, 2008. J Allergy Clin Immunol. 2008;122:254-260.

56. Lee TH, Anderson SD. Heterogeneity of mechanisms in exerciseinduced asthma. Thorax. 1985;40:481-487.

57. Holzer K, Douglass JA. Exercise induced bronchoconstriction in elite athletes: measuring the fall. Thorax. 2006;61:94-96.

58. Crapo RO, Casaburi R, Coates AL, et al. Guidelines for methacoline and exercise challenge testing - 1999. This official statement of the American Thoracic Society was adopted by the ATS Board of Directors, July 1999. Am J Respir Crit Care Med. 2000;161:309-329.

59. Strek PJ, Fabbri LM, Quanjer PH, et al. Airway responsiveness. Standardized challenge testing with pharmacological, physical and sensitizing stimuli in adults. Report Working Party Standardization of Lung Function Tests, European Community for Steel and Coal. Official Statement of the European Respiratory Society. Eur Respir J Suppl. 1993;16:53-83.

60. Dickinson JW, Whyte GP, McConnell AK, Harries MG. Screening elite winter athletes for exercise induced asthma: a comparison of three challenge methods. Br J Sports Med. 2006;40:179-183.

61. Juniper EF, Frith PA, Dunnett C, Cockcroft DW, Hargreave FE. Reproducibility and comparison of responses to inhaled histamine and methacholine. Thorax. 1978;33(6):705-710.

62. Anderson SD, Argyros GJ, Magnussen H, Holzer K. Provocation by eucapnic voluntary hyperpnoea to identify exercise induced bronchoconstriction. Br J Sports Med. 2001;35:344-347. 
63. Holzer K, Anderson SD, Chan HK, Douglass J. Mannitol as a challenge test to identify exercise-induced bronchoconstriction in elite athletes. Am J Respir Crit Care Med. 2003;167:534-537.

64. Voutilainen M, Malmberg LP, Vasankari T, Haahtela T. Exhaled nitric oxide indicates poorly athlete's asthma. Clin Respir J. 2013;7: 347-353.

65. Tantucci C. Expiratory flow limitation definition, mechanisms, methods, and significance. Pulm Med. 2013;2013:749860.

66. McClaran SR, Wetter TJ, Pegelow DF, Dempsey JA. Role of expiratory flow limitation in determining lung volumes and ventilation during exercise. J Appl Physiol (1985). 1999;86:1357-1366.

67. Bussotti M, Agostoni P, Durigato A, et al. Do maximum flowvolume loops collected during maximum exercise test alter the main cardiopulmonary parameters? Chest. 2009;135:425-433.

68. Bjurstedt H, Rosenhamer G, Lindborg B, Hesser CM. Respiratory and circulatory responses to sustained positive-pressure breathing and exercise in man. Acta Physiol Scand. 1979;105:204-214.

69. Koulouris NG, Valta P, Lavoie A, et al. A simple method to detect expiratory flow limitation during spontaneous breathing. Eur Resp J. 1995;8:306-313.

70. Dellacà RL, Santus $\mathrm{P}$, Aliverti A, et al. Detection of expiratory flow limitation in COPD using the forced oscillation technique. Eur Resp J. 2004;23:232-240.

71. Christensen P, Thomsen SF, Rasmussen N, Backer V. Exercise-induced laryngeal obstructions objectively assessed using EILOMEA. Eur Arch Otorhinolaryngol. 2010;267:401-407.

72. Harms C, Stager J. How peripheral chemosensitivity and inadequate hyperventilation contribute to exercise-induced hypoxemia. $J \mathrm{Appl}$ Physiol (1985). 1995;79:575-580.

73. West JB. Invited review: pulmonary capillary stress failure. $J \mathrm{Appl}$ Physiol (1985). 2000;89:2483-2489.

74. Hopkins SR, Schoene RB, Henderson WR, Spragg RG, Martin TR, West JB. Intense exercise impairs the integrity of the pulmonary blood gas in elite athletes. Am J Respir Crit Care Med. 1997;155: 1090-1094.

75. Miles DS, Doerr CE, Schonfeld SA, Sinks DE, Gotshall RW. Changes in pulmonary diffusing capacity and closing volume after running a marathon. Respir Physiol. 1983;52:349-359.

76. Gray GW, Rennie ID, Houston CS, Bryan AC. Phase IV volume of the single breath nitrogen washout curve on exposure to altitude. $J \mathrm{Appl}$ Physiol. 1973;35:227-230.

77. McKenzie DC, Lama IL, Potts JE, Sheel AW, Coutts KD. The effect of repeat exercise on pulmonary diffusing capacity and EIH in trained athletes. Med Sci Sports Exerc. 1999;31:99-104.

78. McKenzie DC, O'Hare TJ, Mayo J. The effect of sustained heavy exercise on the development of pulmonary edema in trained male cyclists. Respir Physiol Neurobiol. 2005;145:209-218.

79. Caillaud C, Serre-Cousiné O, Anselme F, Capdevilla X, Préfaut C. Computerized tomography and pulmonary diffusing capacity in highly trained athletes after performing a triathlon. J Appl Physiol. 1995;79: $1226-1232$.

80. Zavorsky GS, Saul L, Decker A, Ruiz P. Radiographic evidence of pulmonary edema during high-intensity interval training in women. Respir Physiol Neurobiol. 2006;153:181-190.

81. Jambrik Z, Monti S, Coppola V, et al. Usefulness of ultrasound lung comets as a nonradiologic sign of extravascular lung water. Am J Cardiol. 2004;93:1265-1270.

82. Garbella E, Catapano G, Pratali L, Pingitore A. Pulmonary edema in healthy subjects in extreme conditions. Pulm Med. 2011;2011: 275857.

83. Hagen PT, Scholz DG, Edwards WD. Incidence and size of patent foramen ovale during the first 10 decades of life: an autopsy study of 965 normal hearts. Mayo Clin Proc. 1984;59:17-20.

84. Sun XG, Hansen JE, Oudiz RJ, Wasserman K. Gas exchange detection of exercise-induced right-to-left shunt in patients with primary pulmonary hypertension. Circulation. 2002;105:54-60.
85. Kippelen P, Fitch KD, Anderson SD, et al. Respiratory health of elite athletes - preventing airway injury: a critical review. Br J Sports Med. 2012;46:471-476.

86. Vergès S, Flore P, Blanchi MP, Wuyam B. A 10-year follow-up study of pulmonary function in symptomatic elite cross-country skiers: athletes and bronchial dysfunctions. Scand J Med Sci Sports. 2004;14:381-387.

87. Helenius I, Rytilä P, Sarna S, et al. Effect of continuing or finishing high-level sports on airway inflammation, bronchial hyperresponsiveness, and asthma: a 5-year prospective follow-up study of 42 highly trained swimmers. J Allergy Clin Immunol. 2002;109:962-968.

88. Helenius IJ, Tikkanen HO, Haahtela T. Occurrence of exercise induced bronchospasm in elite runners: dependence on atopy and exposure to cold air and pollen. Br J Sports Med. 1998;32:125-129.

89. Kippelen P, Caillaud C, Robert E. Effect of endurance training on lung function: a one year study. Br J Sports Med. 2005;39:617-621.

90. Denguezli M, Ben Chiekh I, Ben Saad H, Zaouali-Ajina M, Tabka Z, Abdelkrim Z. One-year endurance training: effects on lung function and airway inflammation. J Sports Sci. 2008;26:1351-1359.

91. Parsons J, Kaeding C, Phillips G, Jarjoura D, Wadley G, Mastronarde J. Prevalence of exercise-induced bronchospasm in a cohort of varsity college athletes. Med Sci Sports Exercise. 2007;39:1487-1492.

92. Hull JH, Ansley L, Garrod R, Dickinson JW. Exercise-induced bronchoconstriction in athletes - should we screen? Med Sci Sports Exercise. 2007;39:2117- 2124.

93. Carlsen KH, Anderson SD, Bjermer L, et al. European Respiratory Society, European Academy of Allergy and Clinical Immunology; GA(2)LEN. Treatment of exercise-induced asthma, respiratory and allergic disorders in sports and the relationship to doping: Part II of the report from the Joint Task Force of European Respiratory Society (ERS) and European Academy of Allergy and Clinical Immunology (EAACI) in cooperation with GA(2)LEN. Allergy. 2008;63: 492-505.

94. Carlsen KH, Ingjer F, Kirkegaard H, Thyness B. The effect of inhaled salbutamol and salmeterol on lung function and endurance performance in healthy well-trained athletes. Scand J Med Sci Sports. 1997;7:160-165.

95. Papalia SM. Aspects of Inhaled Budesonide use in Asthma and Exercise [Master's thesis]. Department of Human Movement: University of Western Australia; 1996.

96. The Italian Ministry of Public Health. D.M. 18/02/1982 - Norme per la tutela sanitaria dell'attività sportiva agonistica. Gazzetta Ufficiale Stato Italiano 5 marzo 1982, $\mathrm{n}^{\circ} 63$.

97. Lereim I. Sport at Low Temperatures. Prevention of Cold Injuries in Snow Sports. Available from: http://2p3hfwqbf6o3bs9g5tpqw3k05. wpengine.netdna-cdn.com/wp-content/uploads/2012/02/Sport-at-lowtemperatures.pdf. Accessed January 27, 2014.

98. Millqvist E, Bengtsson U, Löwhagen O. Combining a beta2-agonist with a face mask to prevent exercise-induced bronchoconstriction. Allergy. 2000;55:672-675.

99. Carbonnelle S, Bernard A, Doyle IR, Grutters J, Francaux M. Fractional exhaled NO and serum pneumoproteins after swimming in a chlorinated pool. Med Sci Sports Exerc. 2008;40:1472-1476.

100. Daigle CC, Chalupa DC, Gibb FR, et al. Ultrafine particle deposition in humans during rest and exercise. Inhal Toxicol. 2003;15: $539-552$.

101. Hoffman MD, Clifford PS, Varkey B. Acute effects of ski waxing on pulmonary function. Med Sci Sports Exerc. 1997;29:1379-1382.

102. Reiff DB, Choudry NB, Pride NB, Ind PW. The effect of prolonged submaximal warm-up exercise on exercise-induced asthma. Am Rev Respir Dis. 1989;139:479-484.

103. De Bisschop C, Guenard H, Desnot P, Vergeret J. Reduction of exercise-induced asthma in children by short, repeated warm ups. Br J Sports Med. 1999;33:100-104.

104. Morton AR, Hahn AG, Fitch KD. Continuous and intermittent running in the provocation of asthma. Ann Allergy. 1982;48:123-129. 
105. McKenzie DC, McLuckie SL, Stirling DR. The protective effects of continuous and interval exercise in athletes with exercise-induced asthma. Med Sci Sports Exerc. 1994;26:951-956.

106. Global Initiative for Asthma. Global strategy for asthma management and prevention. Updated 2012. Available from: http://www.ginasthma. org/local/uploads/files/GINA_Report_March13.pdf. Accessed February 23, 2014.

107. World Anti-Doping Agency. The World anti-Doping Code. The 2014 Prohibited List. International Standard. Available from: http://www wada-ama.org/Documents/World_Anti-Doping_Program/WADPProhibited-list/2014/WADA-prohibited-list-2014-EN.pdf. Accessed January 13, 2014.

108. Sue-Chu M, Karjalainen EM, Laitinen A, Larsson L, Laitinen LA, Bjermer L. Placebo-controlled study of inhaled budesonide on indices of airway inflammation in bronchoalveolar lavage fluid and bronchial biopsies in cross-country skiers. Respiration. 2000;67: $417-425$
109. Hodges ANH, Lynn BM, Koehle MS, McKenzie DC. Effects of inhaled bronchodilators and corticosteroids on exercise induced arterial hypoxaemia in trained male athletes. Br J Sports Med. 2005; 39:917-920.

110. Weinberger M. Long-acting beta-agonists and exercise. JAllergy Clin Immunol. 2008;122:251-253.

111. Rundell KW, Spiering BA, Baumann JM, Evans TM. Bronchoconstriction provoked by exercise in a high-particulate-matter environment is attenuated by montelukast. Inhal Toxicol. 2005;17:99-105.

112. Prefaut C, Anselme-Poujol F, Caillaud C. Inhibition of histamine release by nedocromil sodium reduces exercise-induced hypoxemia in master athletes. Med Sci Sports Exerc. 1997;29:10-16.

113. Gomes EC, Stone V, Florida-James G. Impact of heat and pollution on oxidative stress and CC16 secretion after $8 \mathrm{~km}$ run. Eur J Appl Physiol. 2011;111:2089-2097.

114. Dry J, Vincent D. Effect of a fish oil diet on asthma: results of a 1-year double-blind study. Int Arch Allergy Appl Immunol. 1991;95: 156-157.

\section{Publish your work in this journal}

Open Access Journal of Sports Medicine is an international, peer-reviewed, open access journal publishing original research, reports, reviews and commentaries on all areas of sports medicine. The manuscript management system is completely online and includes a very quick and fair peer-review system.

\section{Dovepress}

Visit http://www.dovepress.com/testimonials.php to read real quotes from published authors. 